\title{
Infrastructure: An Emerging Global Asset Class
}

\author{
INFLATION-LINKED LONG-DURATION CHARACTERISTICS APPEAL TO PENSION FUNDS
}

By Yves Courtois, CFA

Infrastructure is the backbone of the world economic system. It is instrumental to the economic development of nations and cities, fosters competitiveness and economic growth, and plays a critical role in the flow of international trade. It also shapes the quality of life for individuals and societies by providing access to a broad range of resourcesfrom such basic needs as water, energy, and transportation to more advanced services, such as telecommunications, education, and hospitals.

Only a small fraction of infrastructure assets globally are either under private ownership or listed on an exchange, with the vast majority under the control of governments. Even so, infrastructure is gaining broad recognition among private investors as a distinctive asset class. It is thus a fairly recent phenomenon compared with other asset classes, such as private equity and real estate, and its novelty as an asset class raises some fundamental questions for investors who want to gain exposure. For institutional investors in particular, infrastructure has appealing qualities.

\section{DEFINING TERMS}

Infrastructure is generally defined as the long-lived, large-scale public systems, structures, and facilities that provide essential services to society and the economy. Not all infrastructure is "investible," but the investible asset class is vast and comprises both economic and social infrastructure assets.

Economic infrastructure assets are generally grouped into four categories. (1) Transportation assets include mainly roads, tunnels, bridges, railways, other public transport, airports, and seaports. (2) The utilities category generally comprises electricity and gas networks, water treatment and distribution, and waste management, among others. (3) Energy assets typically include extraction, power generation, oil and gas pipelines, and renewable energy. (4) Communication infrastructure ranges from cable networks to transmission towers to satellites.

Social infrastructure assets provide structures for social services, such as schools and universities, recreation, hospitals, prisons, and administrative buildings.

Some infrastructure assets are also subject to regulations imposed by public authorities to set prices that operators can charge to end users. These regulated infrastructure assets are almost always monopolies, which explains why regulations are imposed on them. Utilities are a classical example of such regulated infrastructure assets.

Infrastructure assets also can be classified according to the kind of financing mechanism used: either project finance or public-private partnerships (frequently called PPP in Europe or P3 in the US). Project finance uses specialpurpose vehicles to share and allocate the risks to the entities that are most suited to manage them. In contrast, PPPs are generally financed through project finance but involve a contract between a public entity and a private contractor, in which the private party delivers a public service and bears risks that are contractually defined.

The various forms of infrastructure investments can be categorized in other ways. One example is greenfield versus brownfield (i.e., whether construction risk is involved or not). Another useful classification is defined by the risk-return profile of infrastructure assets. Low-risk core infrastructure assets, such as social infrastructure or brownfield assets with no revenue risk, have characteristics that are closer to fixed-income instruments. But these assets will never be like perfect bonds because industrial expertise is required to operate these assets and because of the interaction with regulators that frequently is needed. On the other end of the spectrum, opportunistic infrastructure assets, such as satellites or utilities in emerging countries, offer a higher risk-return alternative that shares some similarities with private equity. In between on the risk spectrum, value-added infrastructure involves more active management of the assets, as with renovating an older toll road or managing airports and seaports, which are more subject to the economic cycle.

\section{THE INSTITUTIONAL CONNECTION}

Infrastructure assets generally exhibit long lives and stable and predictable cash flows, provide current income, and have low volatility and low correlation with other asset classes. They also offer partial inflation protection because the services paid by end users or by governments are subject to indexation clauses. Because of their high development costs, most infrastructure assets have major barriers to entry and are consequently less exposed to business cycles.

These characteristics largely explain why infrastructure assets are most appealing to institutional investors with a very long-term perspective seeking sizable initial commitments and exposure to "defensive assets." Given that pension funds are desperate to find inflation-linked long-duration investment opportunities matching their obligations, it is unsurprising to find them being the dominant investors in the asset class. Insurers also have the potential to grow their allocation to infrastructure considerably, especially in the light of the current low-yielding fixed-income environment, but insurers are constrained by the Solvency II EU directive penalizing long maturities.

\section{DRIVING FORCES}

On a global scale, infrastructure investment needs tell two different stories. In advanced economies, underinvestment 
in existing infrastructures has led to massive current investment needs to maintain, upgrade, and modernize these ageing infrastructures. Emerging economies' infrastructure investment needs are fueled by economic and demographic growth and thus, in effect, are about investing in brand new infrastructure assets. These trends largely echo the secular transition taking place

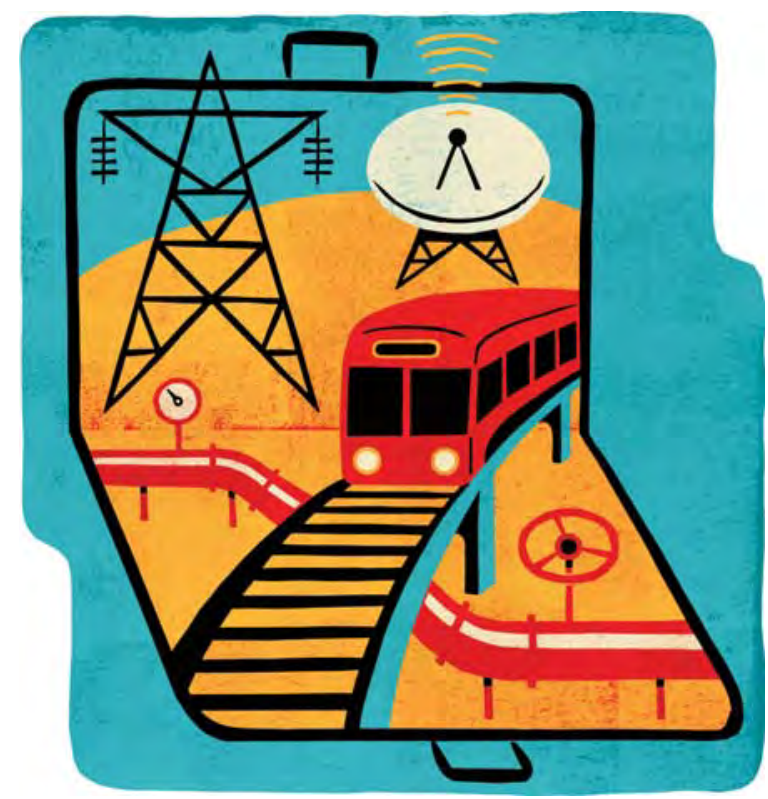

Although the credit crisis created opportunities for the private sector, investment volumes in infrastructure were heavily impacted. According to Preqin data about infrastructure funds' deal flow, investment volumes peaked at US\$192.5 billion in 2007, subsequently dropped by $35 \%$, and since have remained stable, averaging US $\$ 125$ billion per annum. The decline was primarily the result of a sharp drop in average deal size, and the lack of available financing contributed significantly to this decline. Many banks have effectively curtailed their longterm lending exposure to the asset class because of the dramatic circumstances that followed the collapse of Lehman Brothers in 2008 and the stringent capital requirements under Basel III impose new limitations. Banks will remain an important source of financing but will likely operate at the shorter end.

New financing initia-

between advanced and emerging economies. Global infrastructure investment needs over the next 20 years are estimated to range from US $\$ 60$ trillion to US $\$ 100$ trillion or between US\$3 trillion and US\$5 trillion per annum. These numbers dwarf the current private sector role in infrastructure financing and are an indication about the huge growth potential it could represent.

The global credit crisis also had a profound impact on the deterioration of public finances in many OECD countries and on institutional investors' attitude towards risks. On the one hand, the bailouts and the slowing down of economic growth in mature economies have led to a dearth of financing available for the maintenance of existing infrastructure and for new infrastructure; therefore, private capital is expected to bridge part of the financing gap left by governments. On the other hand, institutional investors have reassessed their attitude towards risk and are seeking a long-term asset class with predictable cash flows. tives are coming to market and are adding to the complexity of the investment structuring and the need of advisers to assist in the closing of transactions. The European Investment Bank launched its project bond initiative to boost infrastructure funding in Europe. Many new senior-debt infrastructure funds or managed account platforms, as well as a few institutional investors investing directly in these debt instruments, have been announced in the recent past, and their success will largely depend on their ability to deploy capital. In Europe, the current 10-year record-low number of PPP opportunities in the pipeline does not help. Over the next few years, however, a growing percentage of primary assets will be recycled into the secondary market because many fund managers are now launching their second or third funds and will start to offload assets from their first funds. When the situation of public finance stabilizes in developed markets and the pipeline for large infrastructure projects gets filled, these new forms of financing will likely come to the fore. But any transition in financing will be gradual.

Three countries historically were the cradle for private financing of infrastructure and are now mature and highly sophisticated: Canada, Australia, and the United Kingdom. The rise of European funds has led to an expansion of project finance and PPP throughout Europe. Up until recently, there were expectations that PPP would dramatically boost private investments in US infrastructure. An increasing number of US states and cities have indeed experienced dire financial conditions, and their ability to raise public financing through the municipal bond market has narrowed considerably. In the meantime, some states and cities have passed P3-friendly legislation, creating the conditions for P3 to gain ground relative to municipal bond financing. Before the crisis, the tax-exempt municipal bond market was perceived as the sole credible source of financing for US infrastructures. Instead of a rapid rise, P3 in the US has been gradually building a track record and acquiring respect among market participants. A number of fund managers have also been capturing significant opportunities in the energy sector, notably following the shale gas revolution taking place in the US. Other markets around the world remain largely emerging opportunities for the development of PPP and project financing, even though their growth potential is huge.

\section{GAUGING RISKS}

Most of the risks in an infrastructure project are due to the complexity of the arrangement itself: the documentation, layered sources of financing, degree of technical complexity, applicable regulations, taxation and accounting aspects, and complex and massive financial models. Gaining a proper understanding of specific risks and their evolution over the duration of the project is paramount in infrastructure investing. Four key risks to consider are construction risk, revenue risk, political/regulatory risk, and operating risk.

Construction risk is generally an important and complex source of risk at the beginning of a greenfield project. 
Faulty construction techniques, cost overruns, and delays are examples of what can go wrong in the construction phase. The technical difficulty of construction, adverse weather, design changes, ability to obtain permits, and reputation and experience of the construction company need to be carefully analyzed when assessing construction risk. In the construction phase of a tunnel, for example, geotechnical risk is typically a key risk.

Revenue risk can be a major source of risk in infrastructure when prices and demand for services provided by a newly built infrastructure asset become more volatile than expected in the financial model. Overly optimistic traffic forecasts by consultants have led to several defaults involving toll roads in Australia, with subsequent lawsuits against the consultants.

Political and regulatory risk in infrastructure generally results from adverse regulatory or tax changes impacting the income stream of regulated assets. This category of risks has made headlines, especially in Southern Europe. In Spain, the government decided to changeretroactively-the feed-in tariffs in the alternative energy sector, which resulted in massive losses to investors in that sector. The so-called Robin Hood tax in Italy caused losses for investors in the large photovoltaic farms there. But regulatory risk may also occur in places where it is least expected. For example, when the Norwegian government decided to cut feed-in tariffs by 90\% for Gassled gas transportation contracts, investors were stunned because Norway was perceived at the time as one of the riskless countries in Europe. Going forward, it will be even more critical to understand and analyze in depth the underlying factors causing politicians and regulators to change the rules for regulated assets.

Operating risk is another important source of risk in infrastructure when operating or maintenance costs are higher than expected. As an illustration, consider that when a utility ages, costs of repairs may escalate if the utility is not properly maintained. Also, use of leverage in financing projects may result in higher financing costs than expected or even (in the worst cases) defaults.

\section{VALUATION}

Valuation of infrastructure portfolios requires considerably more expertise, time, and effort than valuation of private equity and real estate. The price-discovery mechanism in infrastructure is particularly challenging because assets are frequently unique in their physical and financing characteristics. Finding available data for truly comparable transactions to use as a benchmark for valuing the portfolio is a daunting task. Likewise, very few assets are listed on an exchange, which limits opportunities for meaningful comparisons. Even indices of publicly listed and traded assets are generally of limited use because they typically are heavily weighted toward water, electricity, gas, and utilities, which are not fully representative of the overall infrastructure asset class.

The infrastructure asset class generally is characterized by a lack of historical data. Many infrastructure fund managers have a relatively limited track record and have performed few clean exits so far. Accordingly, the valuation process requires an extensive analysis of the asset, notably of the cash flow model and of the documentation, to derive an appropriate discount rate that reflects the specific risks of the asset. Those specific risks can be assessed only in relative terms. The use of dividend discount or discounted cash flow models based on free cash flows to equity is the industry norm. Different approaches are used to obtain a discount rate applicable to cash flows. One approach, called the build-up method, adds to an estimate of a longterm risk-free rate all other components of the separately identified and quantified specific risk factors (construction risk, revenue risk, operational risk, and so forth). The build-up method is close to the fundamental approach for valuation. Other methods focus on a pureplay market approach based on the internal rate of return for comparable transactions (if such data are available). For mature brownfield assets, valuation multiples for projected results are frequently used to check the reasonableness of discounted cash flow analysis.

A question arises when some sectors of the infrastructure market are perceived as being a low-risk alternative to low-yielding government bonds, which may lead to inflated prices as a result of overcrowding by investors in a specific market segment. For example, some brownfield assets recently have reached yields below $8 \%$ in Northern Europe, the safest perceived economic zone of the EU. Therefore, a combination of both approaches to estimate discount rates is recommended. In any case, the application of sensitivity analyses on cash flows and elements of the discount rate shed light on the extent of risks and is instrumental in discovering fair value.

More generally, a robust valuation report of the investment portfolio to investors not only should provide an unbiased estimate of value but also should communicate the most salient drivers of cash flow and value and how the various sources of risk are expected to evolve and impact value over time. The complexity of evaluating risk largely explains why the use of independent value reviewers and valuers is far more prevalent in the infrastructure industry than in the private equity industry.

\section{KEY TRENDS}

Investors have a range of options for investing in infrastructure. The more sophisticated, large-scale investors with dedicated infrastructure deal teams prefer direct investing, but the complexity of this asset class limits direct investing to very few investors. At the other end of the spectrum, investing in unlisted infrastructure funds is by far the most common route followed by investors, who select fund managers depending on their skills, track record, and investment style corresponding to their expectations (greenfield, brownfield, low-risk core, medium-risk value added, or high-risk opportunistic infrastructure). Investing in listed infrastructure funds or in shares of companies 
largely exposed to infrastructure is an alternative, albeit less prevalent, way to gain exposure. Co-investing alongside an infrastructure fund is gaining significant ground among investors because it helps them increase their net returns and acquire expertise in deal making. In the current difficult fundraising environment, many fund managers view the creation of a co-investment platform as a way to keep anchor investors and attract new sources of capital to their new funds

Overall, the private investor base has been expanding and broadening. Investor inflows continue to come predominantly from mature markets, such as Canada, the UK, and Australia, but new sources now come from developed Asia, continental Europe, and the US.

Yves Courtois, CFA, is a corporate finance partner at KPMG in Luxembourg, leading the M\&A, valuation, private equity, and infrastructure advisory practices and also co-head of KPMG's Global Valuation Institute. He is a member of CFA Society Luxembourg. This article reflects solely the views of the author and not those of KPMG.

\section{LETTERS}

\section{SEEKING BALANCE ON LIBYA}

I was disappointed that the recent article about North Africa by Chris Wright ("Northern Exposure," July/ August 2013) was unbalanced in the section describing recent events at the Libyan Investment Authority. For the most part, the article is a factual top-down macro analysis of events and the present situation in the region. However, in the discourse on Libya, it relates the experiences of the LIA and specifically its former chairman and chief executive Mohsen Derregia.

I had direct involvement in the LIA as a member of the board of directors during the period of Derregia's tenure. The article paints a very sympathetic picture of Derregia's experiences and exit, which many involved with LIA during this period-whether board directors, trustees, employees-would strongly disagree with. Prime Minister Ali Zidan, in his capacity as chairman of LIA's board of trustees, acted properly in seeking advice and assessment of Derregia's tenure before deciding to replace him in accordance with the law governing the LIA.

I do not want to go into the details or make a case for or against Derregia. I believe that the author should have sought views from a number of stakeholders and presented a balanced case of what happened at the LIA since the revolution. This balanced account is especially necessary in a country where, as Chris Wright highlighted, the prevailing mind set was that "Corruption was a way of life."

Tarik Ben-Saud, CFA

London

\section{DEDICATION. DEVOTION.

Congratulations to our members who

achieved significant Continuing Education

milestones in 2012. Their perseverance in

expanding their knowledge, challenging

their assumptions, and staying up to

speed with our ever-changing profession

continues to inspire us and helps

ensure our global member community

is a vital force shaping a stronger, more

trustworthy investment industry.

See the full list of members who

achieved CE milestones in 2012 at

www.cfainstitute.org/cerecognition. 